\title{
Non-Medical Use of Cognitive Enhancing Prescription Medications Among Occupational Therapy and Speech Language Pathology Health Care Students: A Pilot Study
}

\author{
Randy P. McCombie \\ West Virginia University, rmccombie@hsc.wvu.edu \\ Hannah Slanina \\ Independent Contractor - Occupational Therapist, hslanina@gmail.com
}

Follow this and additional works at: https://nsuworks.nova.edu/ijahsp

Part of the Occupational Therapy Commons

\begin{abstract}
Recommended Citation
McCombie RP, Slanina H. Non-Medical Use of Cognitive Enhancing Prescription Medications Among Occupational Therapy and Speech Language Pathology Health Care Students: A Pilot Study. The Internet Journal of Allied Health Sciences and Practice. 2016 Jan 01;14(2), Article 4.
\end{abstract}

This Manuscript is brought to you for free and open access by the College of Health Care Sciences at NSUWorks. It has been accepted for inclusion in Internet Journal of Allied Health Sciences and Practice by an authorized editor of NSUWorks. For more information, please contact nsuworks@nova.edu. 


\title{
Non-Medical Use of Cognitive Enhancing Prescription Medications Among Occupational Therapy and Speech Language Pathology Health Care Students: A Pilot Study
}

\begin{abstract}
Purpose: This research was designed to serve as a pilot study to generate baseline data on non-medical use of prescription drugs (NMUPD) for cognitive/academic enhancement purposes among students representing two healthcare professions, Occupational Therapy (OT) and Speech Language Pathology (SLP) and to assess students' opinions regarding whether use of these medications constitutes academic "cheating." Introduction: NMUPD, such as Adderall $®$ or Ritalin $\AA$, to reduce fatigue, improve memory, and increase concentration to ultimately improve grades has increased among college students in recent years, with estimated use put as high as $35 \%$ on some campuses. These drugs appear to be readily available to those not prescribed them, with primary sources including family, friends, and classmates. Aside from health concerns stemming from ingesting non-prescribed medications is the ethical concern whether use of such cognitive enhancers is "cheating." Methods: Following IRB approval, 150 OT and 150 SLP students, randomly selected from membership in their respective national associations, were mailed survey packets containing a cover letter, questionnaire, and return envelope. Results: A total of 51 completed surveys, including 25 OT and 26 SLP students, were returned and included in analyses. Of these, five $(9.8 \%)$ reported using cognitive enhancing prescription medications. Four of these reported having a legal prescription, including one who admitted faking symptoms of ADHD to access the prescription. The fifth student had no prescription. Motives included recreational enjoyment, to improve attention/ concentration, reduce hyperactivity/impulsivity, and to obtain higher grades. Four out of ten students indicated abuse of prescription medications was a problem at their institutions, with three out of ten believing it was easy to obtain such drugs. Students were visibly divided as to whether use of these medications was academic cheating. Conclusions: The percent of these healthcare profession students reporting to have used non-prescribed medications for academic enhancement purposes mirrors that of studies on the general college student population and reflects the division as to whether use constitutes cheating. As the survey is a self-report, the numbers using the prescription medications may be higher. Results indicate future research on NMUPD among healthcare students is warranted, along with a need to educate students on the risks of use of these medications for non-prescribed purposes.
\end{abstract}

\section{Author Bio(s)}

- Randy P. McCombie, PhD, OTR/L is Program Director and Chair of the Division of Occupational Therapy, School of Medicine, West Virginia University, Morgantown, WV.

- Hannah Slanina, MOT, OTR/L, is a pediatric occupational therapist working as an independent contractor. 


\title{
IJAHSP \\ The Internet Joưnal of Allied Health Sciences and Practice
}

Dedicated to allied health professional practice and education

Vol. 14 No. 2 ISSN 1540-580X

\section{Non-Medical Use of Cognitive Enhancing Prescription Medications among Occupational Therapy and Speech Language Pathology Health Care Students: A Pilot Study}

\author{
Randy P. McCombie, PhD, OTR/L1 \\ Hannah Slanina, MOT, OTR/L2
}

1. West Virginia University

2. Independent Contractor

United States

\begin{abstract}
Purpose: This research was designed to serve as a pilot study to generate baseline data on non-medical use of prescription drugs (NMUPD) for cognitive/academic enhancement purposes among students representing two healthcare professions, Occupational Therapy (OT) and Speech Language Pathology (SLP) and to assess students' opinions regarding whether use of these medications constitutes academic "cheating." Introduction: NMUPD, such as Adderall $₫$ or Ritalin $₫$, to reduce fatigue, improve memory, and increase concentration to ultimately improve grades has increased among college students in recent years, with estimated use put as high as $35 \%$ on some campuses. These drugs appear to be readily available to those not prescribed them, with primary sources including family, friends, and classmates. Aside from health concerns stemming from ingesting nonprescribed medications is the ethical concern whether use of such cognitive enhancers is "cheating." Methods: Following IRB approval, 150 OT and 150 SLP students, randomly selected from membership in their respective national associations, were mailed survey packets containing a cover letter, questionnaire, and return envelope. Results: A total of 51 completed surveys, including 25 OT and 26 SLP students, were returned and included in analyses. Of these, five (9.8\%) reported using cognitive enhancing prescription medications. Four of these reported having a legal prescription, including one who admitted faking symptoms of ADHD to access the prescription. The fifth student had no prescription. Motives included recreational enjoyment, to improve attention/concentration, reduce hyperactivity/impulsivity, and to obtain higher grades. Four out of ten students indicated abuse of prescription medications was a problem at their institutions, with three out of ten believing it was easy to obtain such drugs. Students were visibly divided as to whether use of these medications was academic cheating. Conclusions: The percent of these healthcare profession students reporting to have used non-prescribed medications for academic enhancement purposes mirrors that of studies on the general college student population and reflects the division as to whether use constitutes cheating. As the survey is a self-report, the numbers using the prescription medications may be higher. Results indicate future research on NMUPD among healthcare students is warranted, along with a need to educate students on the risks of use of these medications for non-prescribed purposes.
\end{abstract}

\section{Literature Review}

The non-medical use of prescription drugs (NMUPD) among college students has become increasingly problematic in recent years. ${ }^{1-4}$ Estimates of the percentage of college students reportedly engaging in NMUPD tend to vary markedly by study. In a review of the research literature on NMUPD, Bogle et al found user rates ranging from a low of $1.4 \%$ to a high of $31 \% .{ }^{5}$ Wilens et al, conducting a similar assessment, also found considerable variation with rates wavering between $5 \%$ and $35 \% .{ }^{6}$ While selfreported reasons for NMUPD include to get high and to stay awake in order to have fun, NMUPD among college students has progressively centered on academic oriented purposes such as enabling one to stay awake longer to study, improve reading comprehension, improve memory, boost higher order cognitive processes such as executive functions, increase concentration to improve performance on tests, and ultimately improve grades. ${ }^{7-13}$ Misuse of prescription medications for purposes of cognitive 
enhancement is looked upon as a method of achieving a socially acceptable goal of attaining good grades, and does not carry the same negative stigma as abusing medications to simply get high. ${ }^{14}$

The drugs typically used for cognitive enhancement purposes include stimulant medications such as Adderall $®$ (mixed salts amphetamine), Concerta $\circledast$ (methylphenidate), Dexedrine $₫$ (dextroamphetamine), Ritalin $®$ (methylphenidate), and a relatively new medication, Provigil $\circledast$ (modafinil).14-16 These medications are often prescribed for patients medically diagnosed with Attention Deficit Hyperactivity Disorder (ADHD). The pharmacological explanations behind the impact of each drug on controlling ADHD symptoms vary by medication. Ritalin $\AA$, for example, is believed to raise dopamine levels by blocking dopamine transporters leading to positive cognitive results such as increased attention, decreased distractibility, and improvements in short-term memory and memory consolidation, representing a corresponding positive effect for those requiring medical assistance, or in the case of non-prescribed use, as a cognitive enhancer. ${ }^{17-19}$ Misuse of these medications, however, has been shown to be associated with increased probability of stimulant induced psychosis, paranoia, stroke, cardiac arrest, and/or sudden death, posing significant potential health threats for those not prescribed the medications. 4,7,20,21

In addition to the health concerns when taking non-prescribed drugs is the ethical dilemma stemming from use of NMUPD for purposes of cognitive enhancement, specifically whether or not it constitutes academic dishonesty or "cheating."22-25 Arguments are usually comparable to those focusing on use of performance enhancing drugs in sports in that NMUPD is seen to provide a distinct and unfair academic advantage. ${ }^{26}$ Interestingly, however, arguments in support of use of academic enhancers do exist. Greely et al, for example, argue in favor of responsible use of cognitive enhancing medications, concluding that "safe and effective cognitive enhancers will benefit both the individual and society."16 Nevertheless, they also point out the need for balance and an evidenced-based approach in considering the benefits and the harms involved in the use of cognitive enhancers.

Overall, it appears that prescription medications are readily accessible to those not personally prescribed them. ${ }^{14,27}$ DeSantis et al found that nearly $85 \%$ of their respondents believed that obtaining such drugs was somewhat or very easy, with roughly nine out of ten users (combined $87 \%$ ) reporting they procured medications from their friends. ${ }^{8}$ Similarly, DuPont et al found that $90 \%$ of those who engaged in NMUPD obtained the medications for free from family members or friends. ${ }^{28}$ On the other hand, students not abusing the prescriptions tend to indicate that they do not know how accessible the medications are on their campus. ${ }^{29}$

While research on NMUPD for the greater part has focused on use by college students in general, some very limited study has centered on NMUPD among students majoring in health care professions. ${ }^{29-33}$ Emanuel et al found $11 \%$ of their sample of medical students used psychostimulants while attending medical school, with a sizeable majority reporting they obtained their medications from family and friends $(48.5 \%)$, classmates $(23.7 \%)$, or acquaintances (13.1\%). ${ }^{31}$ Primary reasons for use included taking the medications to help them study, concentrate, stay awake, increase alertness, and obtain better grades. Wasserman et al found a slightly higher percentage of users in his sample (15.2\%), though the primary use was similar with students reporting using drugs to help them study ${ }^{34}$ Tuttle et al likewise reported the primary NMUPD by a group of medical students to be for improving academic performance, followed by desire to increase alertness and concentration for non-academic purposes. ${ }^{33}$ In a survey of dental and dental hygiene students, McNeil et al found that $12.4 \%$ used a prescription stimulant non-medically, with the majority taking it to improve attention and concentration. ${ }^{29}$ One-third of those taking prescription medications for non-medical purposes reported that it was easy to obtain the medications at their campus, while the majority of those not taking such drugs did not know how easy or difficult it was to obtain such drugs.

Reporting on NMUPD among college students from six healthcare programs (Doctor of Osteopathic Medicine, Medical Health Counseling, Nursing, Occupational Therapy, Physical Therapy, and Physician Assistant), Herman et al found that roughly one in ten (10.4\%) of the students had either used a stimulant in the past or were currently using non-prescription stimulants illegally for academic enhancement purposes. ${ }^{35}$ While the study uniquely included representatives from six programs, studies focusing on healthcare students are rare. Nevertheless, research on the NMUPD among healthcare students is vital as programs admitting these students tend to be highly competitive with graduates ultimately representing an integral component of their healthcare professions..$^{35}$ In sum, this type of competitive environment would appear to set the stage for misuse by those attempting to rise above the competition either in the process of applying to such programs or in striving to succeed in the programs after admitted.

The purpose of the present research was to serve as a pilot study to determine baseline data for NMUPD among student representatives of two healthcare professions, occupational therapy and speech language pathology students. The specific goals of this preliminary research were to 1) assess the prevalence of NMUPD among occupational therapy and speech language pathology students; 2) investigate reasons for using such medications and substances; 3 ) determine perceived ease of availability of these drugs; and, 4) evaluate student opinions as to whether use of such medications constitutes academic dishonesty or "cheating."

(C) The Internet Journal of Allied Health Sciences and Practice, 2016 


\section{Method}

\section{Participants}

The participants for this study included 150 occupational therapy (OT) students and 150 speech language pathology (SLP) students. These participants were randomly selected from membership in their respective national associations, the American Occupational Therapy Association (AOTA) for OT students and the American Speech Language Hearing Association (ASHA) for SLP students. Participants were required to be over the age of 18 years.

\section{Procedure}

Following approval by the University IRB, lists of students' names and addresses were obtained from AOTA and ASHA. All student participants were postal mailed an identical survey packet including a cover letter explaining the nature of the study and their rights as voluntary research participants, a two page, twenty-two item survey that included multiple choice and open-ended questions focusing on their behaviors and beliefs regarding NMUPD within their designated programs, along with a series of demographic questions, and a postage paid return envelope.

Quantitative data were entered into a statistical software program (SPSS $®$ ) and included both descriptive (means, standard deviations, correlations) and inferential (within and between group) analyses. Qualitative data were content analyzed for general themes and categories.

\section{Instrument}

The instrument utilized in the present study included a brief survey questionnaire with both open-ended and closed-ended (yes/no; Likert rating scale) questions. Question items focused on use of targeted prescription medications, and additional substances including alcohol, tobacco, and illegal drugs, along with items addressing ease of access to the medications, and perceptions of whether use constituted academic dishonesty/cheating. Additional questions centered on academic and personal stress reflective of college life. Finally, a demographic section included questions on gender, ethnic/racial background, employment status, grade point average, and academic degree working toward.

\section{Results}

Of the three hundred surveys postal-mailed to participants (150 OT students, 150 SLP students), five were returned due to inaccurate mailing addresses. A total of 51 completed surveys, including 25 OT students and 26 SLP students, were returned and included in the analyses. Any discrepancy in the " $n$ " for any particular analysis from the total sample " $n=51$ " is a result of individual participant non-response for a specific item. The first series of questions provided an overview of the demographic characteristics of the respondents. This information is presented in Table 1. 
Table 1. Demographic characteristics of study participants

\begin{tabular}{|l|c|c|}
\hline Variable & \% & $\mathbf{n}$ \\
\hline Profession & 100.0 & 51 \\
Occupational Therapy (OT) & 49.0 & 25 \\
Speech Language Pathology (SLP) & 51.0 & 26 \\
Sex & & \\
Female & 90.2 & 46 \\
Male & 9.8 & 5 \\
Ethnicity & 96.1 & 51 \\
White, Non-Hispanic & 2.0 & 1 \\
African-American & 2.0 & 1 \\
Hispanic & & \\
Age & 64.7 & 33 \\
20-25 & 21.6 & 11 \\
$26-30$ & 5.9 & 3 \\
$31-40$ & 7.8 & 4 \\
$>40$ & & 2 \\
Degree & 4.0 & 45 \\
Bachelor & 90.0 & 3 \\
Master & 6.0 & \\
Doctorate & & 5 \\
GPA & 10.2 & 8 \\
$3.00-3.25$ & 16.3 & 6 \\
$3.26-3.50$ & 12.2 & 30 \\
$3.51-3.75$ & 61.2 & 27 \\
$3.76-4.00$ & & 24 \\
Employed & 52.9 & \\
Yes & 47.1 & \\
No & & \\
& & \\
\hline
\end{tabular}

The majority of respondents were female $(n=46,90.2 \%)$, with the remainder male $(n=5,9.8 \%)$. The five males were OT students. All but two of the respondents indicated their ethnicity as White, Non-Hispanic (96\%), with one respondent each indicating African American (OT) and Hispanic (SLP). The average age of respondents was 26.63 years $(\mathrm{SD} \pm 7.65)$, ranging from 20 to 58 years. Approximately two-thirds of the respondents (64.7\%) were 25 years of age or younger.

The most commonly indicated graduating degree was a master's ( $n=45,90 \%)$, with two respondents ( $4 \%)$ indicating a bachelor's degree and three respondents $(6 \%)$ indicating a doctoral degree. All but one of the respondents $(n=50,98 \%)$ were full-time students. The mean grade point average of all respondents was $3.73\left(S D_{-}+0.29\right)$, ranging from 3.0 to 4.0 . On the average, participants indicated they spent $22.4(S D \pm 14.37)$ hours per week during the school year in class and lab, ranging from 2 to 80 hours. Respondents also indicated they spent an average of $14.5(\mathrm{SD} \pm 8.26)$ hours per week studying, ranging from 1.5 to 35 hours. When asked if they were employed while attending school, the participants were near evenly split with $27(53 \%)$ indicating "yes" they were employed and the remainder $(n=24,47 \%)$ indicating "no." For those employed, the average number of hours working per week was $16.2\left(S D_{-}+8.91\right)$ hours, ranging from 6 to 40 hours.

The participants were asked to indicate their level/frequency of both academic and interpersonal stress on a five point Likert style scale ranging from $1=$ very stressed, $3=$ occasionally stressed, to $5=$ never stressed. In regard to academic stress, the mean stress rating was $2.12(S D \pm 0.71)$, suggesting that in general these students were "often stressed." The mean rating for interpersonal stress was $2.59(\mathrm{SD} \pm 0.90)$, placing the average stress level between "often stressed" and "occasionally stressed." A Wilcoxon Signed-Ranks Test indicated that the median academic stress rank (median $=2.00$ ) was significantly higher than the median interpersonal stress rank (median $=3.00)(Z=3.131, p=.002)$. A statistically significant negative (Spearman Rho) correlation was found between the level of academic stress and reported GPA $\left(r_{s}(47)=-0.306, p=.033\right)$, such that decreases in GPA were associated with increases in academic stress. 
The next section of the survey focused on use of prescription stimulants and other legal and illegal substances. First, the participants were asked which, if any, of a list of substances they had used in the past month, including alcohol, tobacco, prescription medications in general, and/or recreational drugs. Results found that the majority (80.4\%) of respondents indicated they used alcohol, with smaller percentages found for use of prescription medications in general (13\%), tobacco (3.9\%), and recreational drugs (3.9\%). Of the seven individuals who indicated they used prescription medications, none indicated they used recreation drugs as well.

The students were asked if they were ever prescribed a stimulant medication such as Ritalin $®$, Adderall $\Theta$, Cylert $₫$, Dexedrine $®$, Strattera $\Theta$, or Concerta $\circledast$. Four $(7.8 \%)$ participants indicated they had been prescribed one of the named drugs. Of these, one student reported that they had exaggerated the symptoms of ADD/ADHD in order to receive a prescription. In regard to stimulant medications used in the past academic year, the medications used and number of respondents indicating use were Ritalin $\Omega(n=$ 1), Adderall $(n=3)$, and a combination of Adderall $\Theta$ and Vyvanse $\Theta(n=1)$. These results indicate that while four students reported being prescribed the medications, with one of these exaggerating symptoms in order to secure the prescription, an additional student had access to non-prescribed stimulant medications. Motives for use of stimulants medications included recreation, improving attention/concentration, reducing hyperactivity/impulsivity, and to achieve higher grades. Use of stimulant medication was reported as 2-3 times per year by three respondents, and 1-2 times per day by two respondents. When asked to briefly discuss why they used the stimulant medications replies included

"I use Adderall to help control symptoms of ADD, which in turn allows me to study better and achieve higher grades."

"Adderall - a few times to stay awake on weekend nights to party."

"The stimulants help me focus during studying, after school, usually only use a few during finals week."

"Unable to focus/concentrate on info at hand due to pressure of having to perform well. Have used rarely in extremely stressful situations."

Students were asked if they thought prescription stimulants were a problem or abused by healthcare students at their institution. Responses were varied significantly with $41.2 \%(n=21)$ indicating "yes" ( $3=$ "yes, a very serious problem," 18 = "yes, somewhat of a problem"), $23.5 \%(n=12)$ responding "no, not a problem," and $35.3 \%(n=18)$ indicating "don't know." Responses to this item are presented in Figure 1.

Figure 1. Participant responses to "Do you think prescription stimulants

are a problem, or are abused by health care students at your institution"?

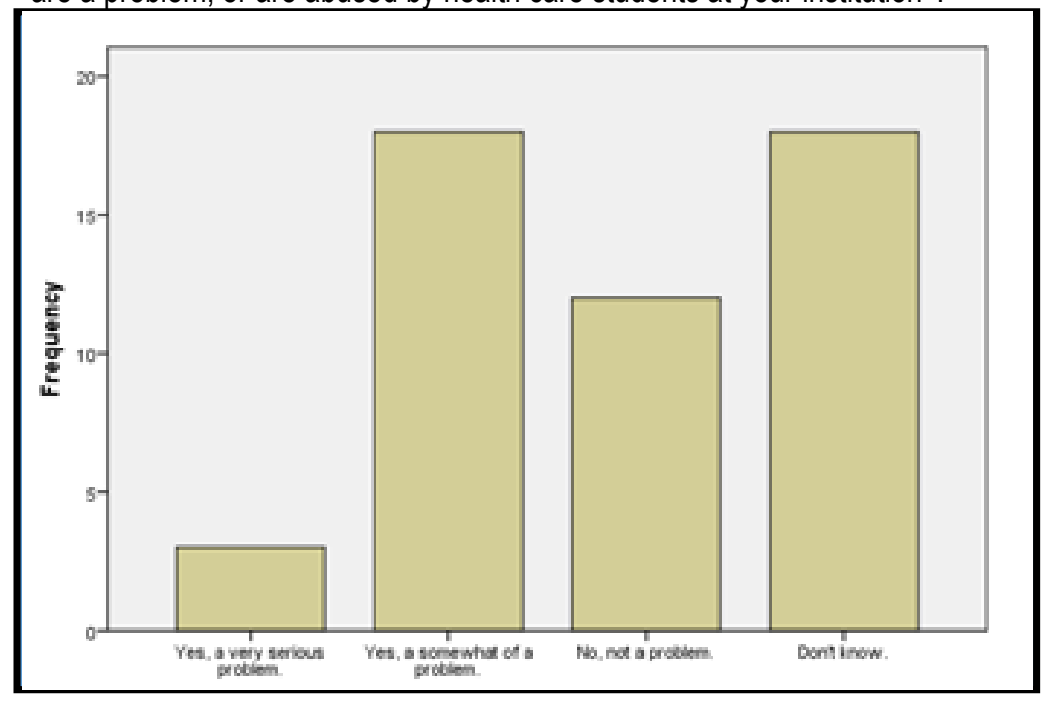

These students were then asked to indicate, in their estimation, how easy or difficult is it for students to acquire non-prescribed stimulant medication(s) at their institution. While the majority $(66.7 \%, \mathrm{n}=34)$ indicated they did not know, roughly three in ten found it "very easy" $(11.8 \%, n=6)$ or "somewhat easy" $(17.6 \%, n=9)$. Only two participants indicated that was "somewhat difficult" $(3.9 \%$, $n=2)$, whereas no students felt it was "very difficult" $(n=0)$. These responses are indicated in Figure 2. 
Figure 2. Participant responses to "How easy or difficult is it for students to acquire non-prescribed stimulant medication(s) at your institution"?

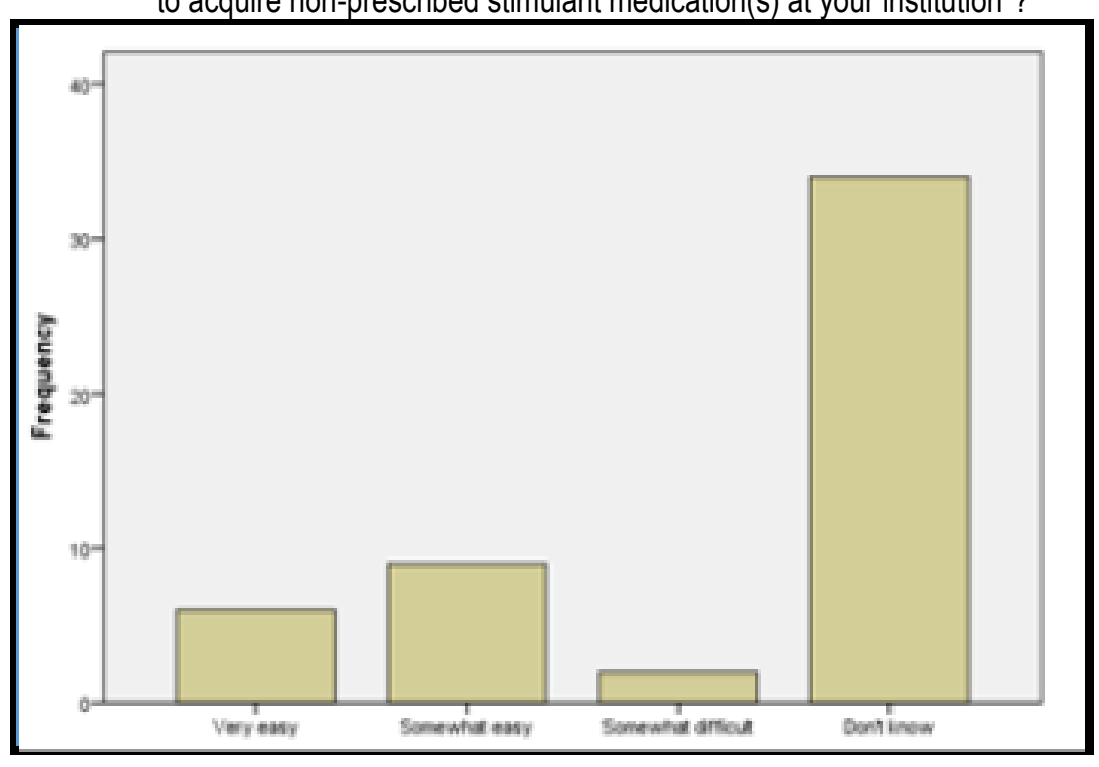

Participants were again provided the opportunity to explain in what way it was easy or difficult in order to provide insight into accessibility. Representative responses included:

"It's easy to get from doctors or other students using them."

"Every student knows many people who are prescribed stimulants. At least one of those people would sell it."

"Know more people in other programs/undergrad who had it - but not abundantly."

Next, the students were asked regardless of whether or not they were taking stimulant medications, did they think those who use stimulant medications solely to improve their academic concentration, improve memorizations, etc. are "cheating"? Interestingly, respondents were comparatively split in their replies to this questions with $42 \%(n=21)$ responding "yes" - those who use stimulant medications to improve academic concentration are cheating, while $58 \%(n=29)$ responded "no" - such individuals are not viewed as cheating.

In regard to the issue of "cheating," participants were asked to briefly discuss their responses. Comments were content-analyzed with three common themes emerging: 1) prescription stimulants are comparable to performance enhancement substances; 2) some individuals have a genuine need for prescription stimulants, and; 3 ) taking non-prescribed stimulants is immoral / unethical. Examples of typical replies included

"If the medication improves concentration and the student is not diagnosed with ADD, it's similar to athletes taking performance enhancing drugs."

"The same way taking steroids is cheating for sports players; the same applies to students' attempts to improve their academic abilities."

"It seems that using the stimulant allows them to focus and study for longer and retain more information than students who aren't abusing stimulants."

"I believe some people really do need it to help them"

"I'm not sure I feel it's cheating, but it does not align with my morals."

\section{Discussion}

This pilot study focused on behaviors and opinions regarding use of prescription stimulant medications among OT and SLP healthcare students. The typical student in this study was female, white/non-hispanic, with a comparatively high GPA, spending nearly 40 hours a week in class or studying towards a master's degree, along with another 16 hours a week working if employed. They reported they were often stressed regarding academics and at least occasionally experienced interpersonal stress. As might be anticipated, given the competitive and demanding nature of the two target academic majors, there was an inverse relationship between GPA and ratings of academic stress. 
The number of students admitting the use of cognitive enhancing prescription medications was approximately one out of ten in this sample, similar to that found in the Herman et al study, with reasons for taking the medications varying from the drug's prescribed and intended use, i.e., help control symptoms of ADD, to personal enjoyment reasons, e.g., stay awake to party, to academic enhancement purposes, e.g., increase cognitive focus in order to improve studying and ultimately achieve better grades. ${ }^{35}$ These proffered reasons mirror those found in previous studies.8,9,11

Compared with non-users, users in this study tended to be slightly younger, have a higher GPA, spend more hours in class but less hours studying, and have lower ratings of academic or interpersonal stress. Frequency of use of the medications noticeably varied from one to two times a day to merely two or three times a year, with the frequency variation dependent upon intent. For example, control of ADHD symptoms required daily usage, while consuming medications for purposes of getting high or for academic enhancement was more specific to the event, i.e., a party or an upcoming exam, and subsequently taken only as desired. Of the five individuals who reported using these enhancement medications, four indicated they had a medical prescription to legally obtain the drugs, although one admitted to exaggerating symptoms of ADHD to secure their prescription. The fifth individual revealed they were not prescribed a medication, in essence using the medication inappropriately and unlawfully. While no information was secured as to where or how that person's medication was obtained, the literature suggests that those not prescribed such drugs tend to acquire them from family, friends, or classmates. ${ }^{28}$

In regard to accessibility, two-thirds of these students simply did not know whether it was easy or difficult to obtain the medications. Roughly three out of ten, however, believed it was easy or very easy to obtain the drugs. Participants were asked to provide additional comments regarding the accessibility of prescription stimulants, and several responders indicated that such substances could be easily acquired from doctors or peers, again reflecting that found in previous research.8,14,27

Two out of five students believed prescription stimulants were a problem or abused by healthcare students at their institution, with only one-fourth concluding it was not a problem. However, a notable percentage, roughly one in three, indicated they did not know whether prescription medication abuse was a problem or not at their institution. If these limited findings are to reflect medication abuse across programs and institutions, there appears to be cause for concern stemming from the percent of students reporting that an abuse problem does exist at their school coupled with a noted percent who either believe it is not a problem or who simply do not know suggesting there likely exists an underground network with access and awareness limited to a select portion of students.

The students were markedly divided in their opinion as to whether use of prescription stimulants, such as Ritalin $\circledast$ or Adderall $\circledast$ with their neural enhancing properties, should be considered academic dishonesty or cheating when taken to improve concentration and memorization. Similarly, arguments presented in the literature reflect this division. ${ }^{36}$ Nevertheless, increased clarification of the reasoning behind the responses in regard to cheating combined with reasons for acceptance of use in academic settings would be of significant benefit in better understanding individual abuse and extent of ethical distress.

While this study found only a small but nonetheless noteworthy portion of OT and SLP students who reported use of prescription stimulant medications, with students often using the medications for purposes other than for their medically prescribed reasons, including cognitive enhancement purposes, it does provide an initial baseline assessment of NMUPD among two groups of healthcare students, one group previously examined only to a minimal extent and the other hitherto never evaluated. Given the competitiveness in admission criteria for such programs, including the generally stringent requirement of a high GPA, combined with the stressors associated with attempting to successfully complete all professional academic work once admitted, the prevalence of NMUPD will likely continue to exist as long as the pressure of academics remains high and/or increases, and as long as access remains relatively easy. Additional research among health care students is needed to more accurately measure depth of use and to assess whether these initial findings are reflective of current use levels among OT and SLP students and endemic to healthcare professional students, and whether use constitutes dishonesty or cheating. Further inquiry is also needed to help determine effectiveness of strategies to eliminate or reduce abuse of these medications and provide assistance to those engaged in or leaning toward non-prescription drug abuse for academic enhancement purposes.

\section{Limitations}

Primary limitations in the present study included the comparatively low return rate likely due in part to traditionally low response rate for postal mail surveys, and in part due to the potentially socially inhibitive nature of the research topic. It is probable that given the illegal usage of prescription medications associated with this type of research, an exact picture of NMUPD may be difficult to paint. In addition, while those not responding may do so out of non-interest or hesitancy due to the nature of the topic, those responding may also have their own inherent biases including a social desirability bias to present oneself in a favorable light or

(C) The Internet Journal of Allied Health Sciences and Practice, 2016 
even a quid pro quo bias in which the participant perceives that by responding, they may receive some positive element in return, e.g., a likelihood of significant return in their own research. Either way, it is necessary to treat survey responses with a degree of caution.

\section{Conclusion}

In summation, this investigation served as a pilot study examining prescription stimulant use among OT and SLP students, with the purpose of achieving four specific research objectives including assessing prevalence of use among these students, reason(s) for use of these medications, perceived ease of medication availability, and whether use construes academic cheating in the opinion of the survey participants. Overall, it was found that roughly ten percent of the students in this sample reported using the targeted prescription medications, with frequency of use and reported purpose varying among user. Opinions regarding ease of accessibility and whether use for academic enhancement purposes constitutes cheating varied considerably among these healthcare students. Given the findings of this pilot study, coupled with the inherent potential for misuse of these medications, further research is encouraged to gain additional insight into prescription medication abuse by healthcare students, along with the formulation of specific recommendations for promoting awareness of the physical and social dangers stemming from the nonmedical use of prescription drugs.

\section{References}

1. Gallucci AR, Usdan SL, Martin RJ, Bolland KA. Pill popping problems: The non-medical use of stimulant medications in an undergraduate sample. Drugs: Educ Prev Polic. 2014;21(3):181-8. doi: 10.3109/09687637.2013.848840

2. McCabe SE, West BT, Wechsler H. Trends and college-level characteristics associated with the non-medical use of prescription drugs among U.S. college students from 1993-2001. Addiction. 2007;102:455-65. [PMID: 17298654]

3. Poulin C. From attention-deficit/hyperactivity disorder to medical stimulant use to the diversion of prescribed stimulants to non-medical stimulant use: Connecting the dots. Addiction. 2007;102:740-51. doi: 10.1111/j.1360-0443.2007.01758.x [PMID: 17506151]

4. Vidourek RA, King KA, Knopf EE. Non-medical prescription drug use among university students. Am J Health Educ. 2010;41(6):345-52.

5. Bogle KE, Smith BH. Illicit methylphenidate use: A review of prevalence, availability, pharmacology, and consequences. Curr Drug Abuse Rev. 2009;2:157-76. [PMID: 19630746]

6. Wilens TE, Adler LA, Adams J, et al. Misuse and diversion of stimulants prescribed for ADHD: A systematic review of the literature. J Am Acad Child Adoles Psychiatry. 2008;47(1):21-31. [PMID: 18174822]

7. Arria AM, O'Grady KE, Caldeira KM, Vincent KB, Wish ED. Non-medical use of prescription stimulants and analgesics: Associations with social and academic behaviors among college students. J Drug Issues. 2008;38:1045-60. [PMID: 20414361]

8. DeSantis $A D$, Webb EM, Noar SM. Illicit use of prescription ADHD medications on a college campus: A multimethodological approach. J Am Coll Health. 2008;57(3):315-23. [PMID: 18980888]

9. Teter CJ, McCabe SE, LaGrange K, Cranford JA, Boyd CJ. Illicit use of specific prescription stimulants among college students: Prevalence, motives, and routes of administration. Pharmacotheraphy. 2006;26:1501-10. [PMID: 16999660]

10. Babcock Q, Byrne T. Student perceptions of methylphenidate abuse at a public liberal arts college. J Am Coll Health. 2000;49(3):143-5. [PMID: 11125642]

11. Ilieva IP, Farah MJ. Enhancement stimulants: perceived motivational and cognitive advantages. Front Neurosci. 2013;7:198. [PMID: 24198755]

12. Pridhomme-White B, Becker-Blease KA, Grace-Bishop K. Stimulant medication use, misuse, and abuse in an undergraduate and graduate student sample. J Am Coll Health. 2006;54:261-8. [PMID: 16539218]

13. Rostain AL. Addressing the misuse and abuse of stimulant medications on college campuses. Curr Psychiatry Rep. 2006;8(5):335-6. [PMID: 16968613]

14. Ford JA, Schroeder RD. Academic strain and non-medical use of prescription stimulants among college students. Deviant Behav. 2009;30(1):26-53. doi:10.1080/01639620802049900

15. Advokat CD, Guidry D, Martino L. Licit and illicit use of medications for attention-deficit hyperactivity disorder in undergraduate college students. J Am Coll Health. 2008;56(6):601-6. [PMID: 18477513]

16. Greely H, Campbell $P$, Sahakian B, et al. Towards responsible use of cognitive-enhancing drugs by the healthy. Nature. 2008;456(7223):702-5. [PMID: 19060880]

17. Gottlieb S. Methylphenidate works by increasing dopamine levels. BMJ. 2001;322(7281):259. [PMID: 11157521]

18. Soetens E, D'Hooge R, Hueting JE. Amphetamine enhances human-memory consolidation. Neurosci Lett. 1993;161(1):9-12. [PMID: 8255556]

19. Zeeuws I, Deroost N, Soetens E. Effect of an acute d-amphetamine administration on context information memory in healthy volunteers: Evidence from a source memory task. Hum Psychopharmacol. 2010;25(4):326-34. [PMID: 20521323]

(c) The Internet Journal of Allied Health Sciences and Practice, 2016 
20. Berman SM, Kuczenski R, McCracken JT, London ED. Potential adverse effects of amphetamine treatment on brain and behavior: A review. Mol Psychiatry. 2009;14(2):123-42. [PMID: 18698321]

21. Iversen L. Speed, Ecstasy, Ritalin: The Science of Amphetamines. New York: Oxford University Press;2006.

22. Bossaer JB, Gray JA, Miller SE, Enck G, Gaddipati VC, Enck RE. The use and misuse of prescription stimulants as "cognitive enhancers" by students at one academic health sciences center. Acad Med. 2013;88(7):967-71. [PMID: 23702522]

23. De Jongh R, Bolt I, Schermer M, Olivier B. Botox for the brain: Enhancement of cognition, mood and pro-social behavior and blunting of unwanted memories. Neurosci Biobehav Rev. 2008;32(4):760-76. [PMID: 18295885]

24. Eneck GG. Ideals of student excellence and enhancement. Neuroethics. 2013;6(1):155-64.

25. Schermer M. On the argument that enhancement is "cheating". J Med Ethics. 2008;34(2):85-8. [PMID: 18234944]

26. Cakic V. Smart drugs for cognitive enhancement: Ethical and pragmatic considerations in the era of cosmetic neurology. J Med Ethics. 2009;35:611-5. [PMID: 19793941]

27. Quintero H. Controlled release: A cultural analysis of collegiate polydrug use. J Psychoactive Drugs. 2009;41(1):39-47. [PMID: 19455908]

28. DuPont RL, Coleman JJ, Bucher RH, Wilford BB. Characteristics and motives of college students who engage in nonmedical use of methyphenidate. Am J Addict. 2008;17(3):167-71. [PMID: 18463991]

29. McNeil AD, Muzzin KB, DeWald JP, et al. The nonmedical use of prescription stimulants among dental and dental hygiene students. J Dent Educ. 2011;75(3):365-76. [PMID: 21368261]

30. Coleman EA, Honeycutt G, Ogden B, et al. Assessing substance abuse among health care students and the efficacy of educational interventions. J Prof Nurs. 1997;13(1):28-37. [PMID: 9183110]

31. Emanuel RM, Frellsen SL, Kashima KJ, Sanguino SM, Sierles FS, Lazarus CJ. Cognitive enhancement drug use among future physicians: Findings from a multi-institutional census of medical students. J of Gen Intern Med. 2013;28(8):102834. [PMID: 23595918]

32. Low KG, Gendaszek AE. Illicit use of psychostimulants among college students: A preliminary study. Psychol Health Med. 2002;7(3):283-7. doi: 10.1080/13548500220139386

33. Tuttle JP, Scheurich NE, Ranseen J. Prevalence of ADHD diagnosis and nonmedical prescription stimulant use in medical students. Acad Psychiatry. 2010;34(3):220-3. [PMID: 20431104]

34. Wasserman JA, Fitzgerald JE, Sunny MA, Cole M, Suminski RR, Dougherty JJ. Nonmedical use of stimulants among medical students. J Am Osteopath Assoc. 2014;114(8) 643-53. [PMID: 25082972]

35. Herman L, Shtayermman O, Aksnes B, Anzalone M, Cormerais A, Liodice C. The use of prescription stimulants to enhance academic performance among college students in health care programs. J Physician Assist Educ. 2011;22(4):15-22. [PMID: 22308929]

36. Whetstine LM. Cognitive enhancement: Treating or cheating? Semin Pediatr Neurol. 2015;22(3):172-6. [PMID: 26358427] 